\title{
Potential of Fruit Peel Waste in Growing Cyanobacteria Anabaena cylindrica
}

\author{
Tan Yeong Hwang1, Ho An $\mathrm{Qi}^{2}$, Chai Mee Kin${ }^{1}$, Wong Ling Shing ${ }^{2}$, \\ Sinouvassane Djearamane ${ }^{3}$, Chinnasamy Thirunavukkarasu ${ }^{4}$ \\ ${ }^{1}$ College of Engineering, Universiti Tenaga Nasional, Jalan Ikram-Uniten, Kajang, Selangor 43000, Malaysia \\ ${ }^{2}$ Faculty of Health and Life Science, INTI International University, Persiaran Perdana BBN, Putra Nilai, Nilai, \\ Negeri Sembilan 71800, Malaysia \\ ${ }^{3}$ Faculty of Science, Universiti Tunku Abdul Rahman, Kampar, Perak 31900, Malaysia \\ ${ }^{4}$ Department of Biochemistry and Molecular Biology, Pondicherry University, Puducherry 605014, India
}

\begin{abstract}
Fruit peels are usually disposed of or treated as fertilizer. The peel, however, contains rich nutrients that can be used as a medium for growing microbes. Conventional culture medium is widely used for growing microbes, but the cost is very high and it is not suitable to produce cyanobacterium-based biofuel, biomass, and in other applications. Therefore, this study explores the potential for using fruit peels as a culture medium for Anabaena cylindrica. The fruit peels were dried, homogenized, and filtered to make different concentrations of fruit peel media $(5 \%, 10 \%$ and $20 \%)$. For comparison, BG-11 medium acted as a positive control whereas deionized water serves as a negative control in this experiment. Growth of $A$. cylindrica in different types of media was analyzed after cell counting using a hemacytometer and biomass measuring. The cyanobacterial growth rate and biomass production were recorded in different types of fruit peel media with different concentrations. A. cylindrica have greater biomass yield when growing in $20 \%$ papaya peel medium and a higher growth rate when growing in $10 \%$ pineapple peel media compared to that growing in the BG-11 medium. In other words, the fruit peel media have more potential in growing cyanobacteria than conventional medium.
\end{abstract}

Keywords: Agriculture waste; Biomass production; Cell culture

\section{Introduction}

Anabaena cylindrica are cyanobacteria which belong to the Anabaena species and are found to appear singly or in a chain of cells. Their vegetative cells possess the capability to carry out carbon dioxide fixation and nitrogen fixation simultaneously. Besides vegetative cells, $A$. cylindrica can transform into two cell types that are heterocysts and akinetes (Hori et al., 2002). Nitrogen fixation will develop when nitrogen is limited (Heng et al., 2014). Heterocysts would suppress nearby cells from developing into another heterocyst, but adjacent vegetative cells will be procured to transform into akinetes, which have a thick cell wall (Qiu et al., 2018). Although both of these specialized cells cannot carry out photosynthesis, they can resist in the adverse environment and grow back into a vegetative cell in a favorable environment (Sukenik et al., 2019).

Many investigations have been done on cyanobacterium biomass, including the Anabaena species, to produce environmentally friendly biofuel products, such as bio-

${ }^{*}$ Corresponding author's email: lingshing.wong@newinti.edu.my, Tel.: +606-7182000 Fax.: +606-7997531 doi: 10.14716/ijtech.v12i4.4852 
hydrogen, bio-methane, and biodiesel (Patel et al., 2018; Vargas et al., 2018). Additionally, cyanobacteria have economic applications in the nutrition, cosmetic, and pharmaceutical industries due to their valuable co-products (Hamouda et al., 2017; Singh et al., 2017). However, there are challenges in growing cyanobacteria. One of them is the high cost of culture medium (deCastro et al., 2015). Large amount of media is needed in extensive practical studies for cultivation, streak plate or pour plate and other experiments but low cost media is less available. Therefore, there were studies finding alternatives to these expensive commercial medium (deCastro et al., 2015; Beyl et al., 2019; Jiang et al., 2019).

Due to extensive agricultural exercises nowadays, there have been many vegetables and fruit produced daily in Malaysia (Grünwald, 2021). Papaya, pineapple, mango, and banana are fruits that are most widely consumed by Malaysians or used for the food industry (Rozhan, 2017). About $40 \%$ of the fruit's total mass is made up from the inedible portion like peels, seeds, and pulps (Cheok et al., 2018). Some irresponsible people would dispose of these unwanted fruit parts improperly into the environment, leading to environment pollution (Gowe, 2015; Tonini et al., 2018). The dumping site that accumulates this fruit waste becomes the culture area of pathogenic bacteria, fungi, or yeast (Cheok et al., 2018), and produces leachate that pollutes ground water and affect aquatic life (Ali et al., 2014).

Fruit wastes are cheap organic ingredients because they are readily available as domestic waste. Moreover, they consist of high amounts of sugar that can be utilized by cell (Katiyar et al., 2019; Mohammed et al., 2020). Fruit also contains various kinds of minerals and other hydrocarbons in the form of carbohydrates, protein, and lipids (SeptembreMalaterre et al., 2016). Therefore, it would be better if there was potential for using fruit wastes to design a culture medium for cyanobacteria. It would eliminate the consequences associated with improperly disposed fruit residues.

To date, there are reports showing that fruit peels have been used for formulation in culture medium for microbial (Sarkar et al., 2019), fungal (Choi et al., 2015; Anbu et al., 2017), and yeast (Dhanasekaran et al., 2011) growth, but their capacity to cultivate cyanobacteria has not been confirmed yet. Hence, the research aims to find out the potential of growing cyanobacteria by biological waste from fruits such as mango, papaya, and pineapple. The growth of one commonly available cyanobacteria, A. cylindrica, on the medium produced from the fruit waste is determined as well.

\section{Methods}

\subsection{Microalgae Strain Cultivation}

An A. cylindrica culture (1403/2A) was obtained from CCAP, United Kingdom. The cells were cultured into two separate sterile Erlenmeyer flasks containing $200 \mathrm{~mL}$ of fresh BG11 medium. The flasks were covered with gauze and a rubber band. The cultures were incubated in $22-24{ }^{\circ} \mathrm{C}$ under illumination from cool-white fluorescent tubes with 16:8 hours of light-dark cycle. As no air was pumping into the cell culture during the short period of the experiment, continuous shaking was not utilized (Hsia et al., 2015). Gentle shaking of liquid culture was done every day to avoid microalgae adherence and congregation. Growth phases of the cells were investigated by determining cell density (Equation 1) using a hemocytometer (Marienfeld-Superior, Neubauer) under a light microscope (Eclipse E-100 LED, Nikon);

Cell density $($ cells $/ \mathrm{mL})=$ Average number of cells per field $\times 10^{4} \times$ dilution factor 


\subsection{Fruit Peel Collection and Treatment}

The pineapple, mango, and papaya fruits were purchased at a local supermarket. The fruit peels were removed and dried using a drying oven with temperatures between 40 and $50^{\circ} \mathrm{C}$. The papaya peels were homogenized using a Faber blender. Then, the homogenized papaya peels were filtered by using filter paper to remove the large solid residues before being transferred into Duran glass bottles and labelled. They were heated in a microwave oven at $200 \mathrm{~W}$ for 5 minutes to reduce the potential microorganism activity. The bottles were wrapped with aluminum foil and kept in the refrigerator at $4^{\circ} \mathrm{C}$ to avoid nutrient decomposition. This procedure was repeated for pineapple and mango peels.

\subsection{Microalgae Cultivation with Fruit Peel Medium}

All of the fruit peel media were diluted into concentrations of $5 \%, 10 \%$, and $20 \%$ with distilled water for a final volume of $200 \mathrm{~mL}$ with $\mathrm{pH}$ between 5.0-6.0. Each diluted fruit peel medium was cultivated with $3 \mathrm{~mL}$ or $4.7 \times 10^{7}$ cells $/ \mathrm{mL}$ of 5 -days-old A cylindrical. Microalgae cultivation with BG-11 and deionized water was used as positive and negative controls, respectively. The microalgae were cultivated previously described.

\subsection{Determination of Microalgae Cell Growth}

The initial dry biomass of culture growing in every media was measured on their day zero of cultivation. Their dry biomass was also measured on every two days of cultivation. Ten milliliters of cell culture was taken out from each kind of medium and put on mixed cellulose ester membrane filters with absorbent pads $(0.45 \mu \mathrm{m}$ pore size, $47 \mathrm{~mm}$ in diameter). Then, they were vacuum-filtered by a Büchner funnel. Each loaded filter was dried in a drying oven at $70^{\circ} \mathrm{C}$ until the weight was constant. Then, the weight of the membrane filter with the cyanobacterial dry load was measured. Cyanobacterial dry biomass was obtained by calculating the difference of the weight between the pure dried membrane filter and the membrane filter with cyanobacterial dry load.

Dry biomass was used to calculate the microalgae growth by biomass concentration (Equation 1), productivity (Equation 2), and specific growth rate (Equation 3).

$$
\text { Biomass concentration }=\frac{\text { Dry biomass }}{V_{a}}-\frac{\text { Dry biomass }}{V_{a}}
$$

where Va is the volume of aliquots.

$$
\text { Biomass productivity, } P_{b}=\frac{\left(N_{f}-N_{0}\right)}{\left(t_{f}-t_{0}\right)}
$$

where $\mathrm{N}_{\mathrm{f}}$ and $\mathrm{N}_{0}$ are the biomass concentration $(\mathrm{g} / \mathrm{L})$ on days $\mathrm{t}_{\mathrm{f}}$ and to (the end and beginning of the determined growth phase, respectively).

$$
\text { Specific growth rate, } \mu=\frac{\ln \left(N_{f}-N_{0}\right)}{\left(t_{f}-t_{0}\right)}
$$

\subsection{Statistical Analysis}

All experiments were conducted in triplicate and data were presented as means \pm standard error of the mean.

\section{Results and Discussion}

The biomass productivity of $A$. cylindrica grown in different concentrations of fruit peel media was illustrated in Figure 1. From Figure 1a, the biomass concentration in all 5\% media is similar with BG-11 medium. Only the cells cultivated in 5\% pineapple and mango 
peel media showed slightly higher biomass concentrations. As illustrated in Figure $1 \mathrm{~b}$, the biomass concentration in $10 \%$ papaya peel media was observed much higher than those cells grew in the BG-11 medium whereas the biomass concentration in $10 \%$ mango and pineapple peel media was similar to BG-11 medium throughout the cultivation period. Although the greatest concentration of biomass was produced by cells cultivated in $10 \%$ pineapple peel media at day 1, the biomass concentration was dropped at day 3 and then slowly increased thereafter. This is probably due to the presence of contaminated microorganisms. These medium were not autoclaved to reduce the cultivation cost and therefore have the potential of contamination. Presence of contaminated microorganisms competed nutrient sources with $A$. cylindrica thereby reduced the biomass concentration. As shown in Figure 1c, the biomass concentration of cells cultivated in 20\% papaya and pineapple peel media is higher than cells grown in BG-11, whereas the biomass concentration in $20 \%$ mango peel medium showed a similar trend compared to BG-11 medium.

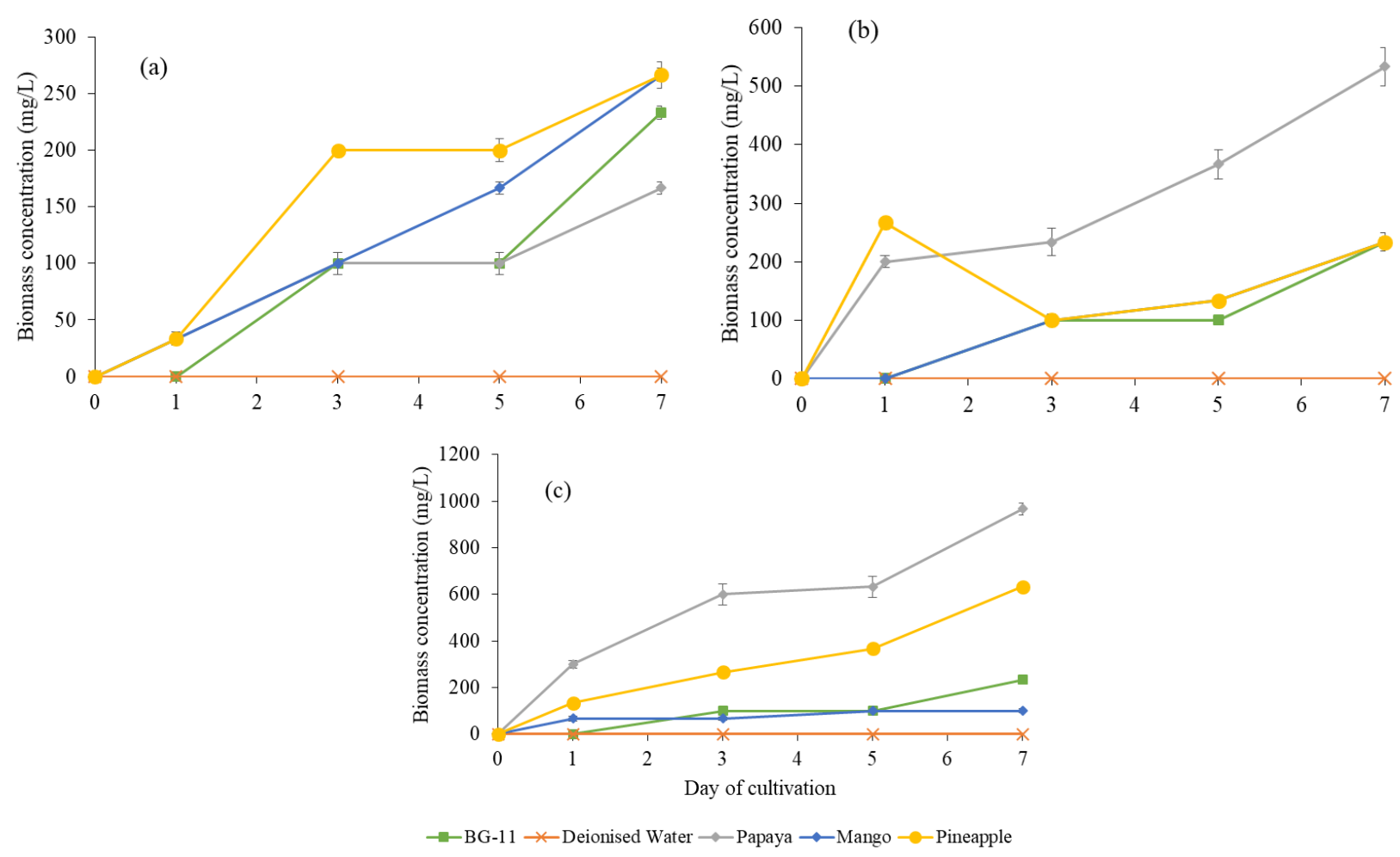

Figure 1 Biomass concentration of $A$. cylindrica in: (a) 5\%; (b) 10\%; and (c) 20\% papaya, pineapple, and mango peel and BG-11 medium $(\mathrm{n}=3)$

Generally, papaya, pineapple, and mango peel are abundant with various nutrients, such as organic carbon, protein, vitamins, and trace metals (Abdul Aziz et al., 2012; Roha et al., 2013; Souza et al., 2016; Pavithra et al., 2017) which can be supplemented to support $A$. cylindrica growth. Previous studies revealed that high concentrated waste has negative impacts on some microalgal growth (Lau et al., 2014; Sloth et al., 2017). Concentrated waste medium is usually dark in color, which reduces the light penetration to it. As a result, the phototrophic or mixotrophic microalgae, which require light as part of their metabolism, may slow down their growth. Nevertheless, this study showed contrary results that high final biomass concentration with high specific growth rate and biomass productivity was observed in $10 \%$ and $20 \%$ pineapple and papaya peel media. On the other hand, the biomass productivity and specific growth rate in most concentrations of papaya and 
pineapple peel media are better than the BG-11 medium (Table 1). This phenomena can be elucidated by two hypotheses. First, unlike the cells in the BG-11 medium which are green, the cells in high concentrated fruit peel medium showed low intensity of green and were almost colorless. This indicated that the chlorophyll content of the cell decreased and they probably did not perform photosynthesis. Hence, it can be deduced that $A$. cylindrica probably carried out heterotrophic growth. The literature has demonstrated that some of the cyanobacteria can become chemoorganoheterotrophic by using simple carbohydrates without a light supply (Stebegg et al., 2012). Although the mechanisms behind Anabaena assimilation of organic carbon and nitrogen have not been greatly determined, Herrero and Flores (2019) predict that, in a harsh environment, genes for heterocyst differentiation will be activated then followed by activation of genes involved in glycogen catabolism, glycolysis, and the pentose phosphate pathway. Wan et al. (2017) revealed that, during dark and heterotrophic conditions, an oxidative pentose phosphate pathway and oxidative phosphorylation were upregulated so that cyanobacteria was able to catabolize simple sugar in order to produce energy. In another study, Nieves-Morión and Flores (2018) found that the Anabaena species was able to grow in the presence of glucose, sucrose, and fructose by activating the $A B C$ glucoside transporter and other $A B C$ transporters which are responsible for sugar uptake. These studies suggest that cyanobacteria, including Anabaena, are capable of photoautotrophic, organoheterotrophic, and mixotrophic growth.

Second, the fruit peel media were not sterile, posing the possibility of contamination. Compared to the BG-11 medium, microorganisms are preferred to grow in fruit peel medium that is comprised of abundant organic nutrient. These microorganisms might have beneficial responses to $A$. cylindrica by exchange of nutrients, excreting growth-promoting compounds, vitamins, and protecting from competitors (Ma et al., 2014; Cho et al., 2015). Paddock et al. (2020) suggested that the presence of a complex microbial community in wastewater can enhance wastewater treatment and biomass production.

In summary, the cultivation of $A$. cylindrica with papaya, pineapple, and mango media showed promising results for cyanobacterial growth. Among all the experimental controls, the highest biomass concentration was performed by cells grown in $20 \%$ of papaya peel medium ( $933.33 \mathrm{mg} / \mathrm{L})$ whereas the lowest biomass concentration was performed by cells grown in $20 \%$ of mango peel medium which was only $100.00 \mathrm{mg} / \mathrm{L}$. On the other hand, the highest growth rate of cells was observed in $10 \%$ pineapple peel medium while the lowest growth rate of cells was observed in $20 \%$ mango peel medium. Moreover, the biomass concentration did not increase much in the mango peel medium even though the concentration of mango peel medium was increased from 5\% to $20 \%$. The biomass productivity and specific growth rate in mango peel medium was also lower than the same concentration of papaya and pineapple peel media (Table 1). This can be explained by a high level of polysaccharides, especially pectin or starch in mango peel (Iagher et al., 2002). The growth of microalgae was inhibited because the polysaccharides in the culture medium increased the concentration polysaccharide in the cell wall, thus disrupting the nutrient uptake or nutrient diffusion (Rotem et al., 1992). Inhibition of carbon uptake would deter the cells from performing photosynthesis. 
Table 1 Final biomass concentration, biomass productivity, and specific growth rate of $A$. cylindrica in fruit peel and BG-11 medium

\begin{tabular}{lcccc}
\hline Medium & & $\begin{array}{c}\text { Final biomass } \\
\text { concentration }(\mathrm{mg} / \mathrm{L})\end{array}$ & $\mathrm{P}_{\mathrm{b}}(\mathrm{mg} / \mathrm{L} /$ day $)$ & $\mu\left(\right.$ day $\left.^{-1}\right)$ \\
\hline BG-11 & & $233.33 \pm 5.77$ & $17.33 \pm 0.165$ & $0.167 \pm 0.032$ \\
DW & $0.00 \pm 0.000$ & $0.00 \pm 0.000$ & $0.000 \pm 0.000$ \\
Papaya & $5 \%$ & $166.67 \pm 5.74$ & $22.10 \pm 1.72$ & $0.122 \pm 0.041$ \\
& $10 \%$ & $533.33 \pm 32.15$ & $85.46 \pm 5.46$ & $0.205 \pm 0.077$ \\
Pineapple & $5 \%$ & $933.33 \pm 5.75$ & $152.95 \pm 9.04$ & $0.344 \pm 0.132$ \\
& $10 \%$ & $266.67 \pm 11.55$ & $35.62 \pm 1.88$ & $0.191 \pm 0.135$ \\
& $266.67 \pm 15.28$ & $72.00 \pm 2.49$ & $0.366 \pm 0.039$ \\
Mango & $5 \%$ & $633.37 \pm 25.17$ & $77.24 \pm 2.84$ & $0.116 \pm 0.025$ \\
& $10 \%$ & $266.67 \pm 5.75$ & $27.62 \pm 2.22$ & $0.135 \pm 0.153$ \\
& $20 \%$ & $100.00 \pm 10.01$ & $18.67 \pm 3.96$ & $0.122 \pm 0.024$ \\
& & & $24.63 \pm 2.98$ & $0.084 \pm 0.008$ \\
\hline
\end{tabular}

\section{Conclusions}

A. cylindrica grew successfully on the nutrient-rich fruit peel medium. The biomass concentration, productivity, and specific growth rate were enhanced when cultivating in fruit peel media. Fruit peel media have the potential to replace the expensive chemicallysynthetic medium. From the experiment, A. cylindrica was able to produce its greatest biomass in a $20 \%$ papaya medium and possesses the highest growth rate in a $10 \%$ pineapple peel medium.

\section{Acknowledgements}

The Universiti Tenaga Nasional, Malaysia (Bold Grant: 10436494/B/2019006) supported this project.

\section{References}

Abdul Aziz, N.A., Wong, L.M., Bhat, R., Cheng, L.H., 2012. Evaluation of Processed Green and Ripe Mango Peel and Pulp Flours (Mangifera indica var. Chokanan) in Terms of Chemical Composition, Antioxidant Compounds and Functional Properties. Journal of the Science of Food and Agriculture, Volume 92(3), pp. 557-563

Ali, S.M., Pervaiz, A., Afzal, B., Hamid, N., Yasmin, A., 2014. Open Dumping of Municipal Solid Waste and its Hazardous Impacts on Soil and Vegetation Diversity at Waste Dumping Sites of Islamabad City. Journal of King Saud University - Science, Volume 26(1), pp. 5965

Anbu, S., Saranraj, P., Padma, J., Punithavalli, K., 2017. Fruits Peel Waste as a Novel Media for the Growth of Economically Important Fungi. Journal of Pharmacognosy and Phytochemistry, Volume 6(6), pp. 426-428

Beyl, T., Louw, T.M., Pott, R.W.M., 2019. Cyanobacterial Growth in Minimally Amended Anaerobic Digestion Effluent and Flue-gas. Microorganisms, Volume 7(10), pp. 1-26

Cheok, C.Y., Mohd Adzahan, N., Abdul Rahman, R., Zainal Abedin, N.H., Hussain, N., Sulaiman, R., Chong, G.H., 2018. Current Trends of Tropical Fruit Waste Utilization. Critical Reviews in Food Science and Nutrition, Volume 58(3), pp. 335-361

Cho, D.H., Ramanan, R., Heo, J., Lee, J., Kim, B.H., Oh, H.M., Kim, H.S., 2015. Enhancing Microalgal Biomass Productivity by Engineering a Microalgal-bacterial Community. Bioresource Technology, Volume 175, pp. 578-585 
Choi, I.S., Lee, Y.G., Khanal, S.K., Park, B.J., Bae, H.J., 2015. A Low-energy, Cost-effective Approach to Fruit and Citrus Peel Waste Processing for Bioethanol Production. Applied Energy, Volume 140, pp. 65-74

deCastro, G., Rizzo, S., Passos, T.S., Santos, B., Dias, D., Domingues, J., Araújo, K., 2015. Biomass Production by Arthrospira Platensis under Different Culture Conditions. Food Science and Technology, Volume 35(1), pp. 18-24

Dhanasekaran, D., Lawanya, S., Saha, S., 2011. Production of Single Cell Protein from Pineapple Waste. Innovative Romanian Food Biotechnology, Volume 8, pp. 26-32

Gowe, C., 2015. Review on Potential Use of Fruit and Vegetables By-products as a Valuable Source of Natural Food Additives. Food Science and Quality Management, Volume 45, pp. 47-61

Grünwald, N.J., 2021. Entering the International Year of Fruits and Vegetables: Tradeoffs Between Food Production and the Environment. CABI Agriculture and Bioscience, Volume 2(2), pp. 1-3

Hamouda, R.A., Al-Saman, M.A., El-Sabbagh, S.M., El-Seoud, G.W.A., Hendawy, A.N., 2017. Approach to Improve the Productivity of Bioactive Compounds of the Cyanobacterium Anabaena Oryzae using Factorial Design. Egyptian Journal of Basic and Applied Sciences, Volume 4(3), pp. 190-195

Heng, R.L., Lee, E., Pilon, L., 2014. Radiation Characteristics and Optical Properties of Filamentous Cyanobacterium Anabaena Cylindrica. Journal of the Optical Society of America, Volume 31(4), pp. 836-845

Herrero, A., Flores, E., 2019. Genetic Responses to Carbon and Nitrogen Availability in Anabaena. Environmental Biology, Volume 21(1), pp. 1-17

Hori, K., Ishii, S.I., Ikeda, G., Okamoto, J.I., Tanji, Y., Weeraphasphong, C., Unno, H., 2002. Behavior of Filamentous Cyanobacterium Anabaena Spp. in Water Column and its Cellular Characteristics. Biochemical Engineering Journal, Volume 10, pp. 217-225

Hsia, S.Y., Yang, S.K., 2015. Enhancing Algal Growth by Stimulation with LED Lighting and Ultrasound. Journal of Nanomaterials, Volume 2015, pp. 1-11

Iagher, F., Reicher, F., Ganter, J.L.M.S., 2002. Structural and Rheological Properties of Polysaccharides from Mango (Mangifera indica L.) Pulp. International Journal of Biological Macromolecules, Volume 31(1-3), pp. 9-17

Jiang, L., Sun, J., Nie, C., Li, Y., Jenkins, J., Pei, H., 2019. Filamentous Cyanobacteria Triples Oil Production in Seawater-based Medium Supplemented with Industrial Waste: Monosodium Glutamate Residue. Biotechnology for Biofuels, Volume 12, pp. 1-16

Katiyar, R., Gurjar, B.R., Kumar, A., Bharti, R.K., Biswas, S., Pruthi, V., 2019. A Novel Approach using Low-cost Citrus Limetta Waste for Mixotrophic Cultivation of Oleaginous Microalgae to Augment Automotive Quality Biodiesel Production. Environmental Science and Pollution Research, Volume 26, pp. 16115-16124

Lau, K.Y., Pleissner, D., Lin, C.S.K., 2014. Recycling of Food Waste as Nutrients in Chlorella Vulgaris Cultivation. Bioresource Technology, Volume 170, pp. 144-151

Ma, X., Zhou, W., Fu, Z., Cheng, Y., Min, M., Liu, Y., Zhang, Y., Chen, P., Ruan, R., 2014. Effect of Wastewater-borne Bacteria on Algal Growth and Nutrients Removal in Wastewaterbased Algae Cultivation System. Bioresource Technology, Volume 167, pp. 8-13

Mohammed, S., Edna, M., Siraj, K., 2020. The Effect of Traditional and Improved Solar Drying Methods on the Sensory Quality and Nutritional Composition of Fruits: A Case of Mangoes and Pineapples. Heliyon, Volume 6(6), pp. 1-10

Nieves-Morión, M., Flores, E., 2018. Multiple ABC Glucoside Transporters Mediate Sugarstimulated Growth in the Heterocyst-forming Cyanobacterium Anabaena Sp. Strain PCC 7120. Environmental Microbiology Reports, Volume 10(1), pp. 40-48 
Qiu, Y., Tian, S., Gu, L., Hildreth, M., Zhou, R., 2018. Identification of Surface Polysaccharides in Akinetes, Heterocysts and Vegetative Cells of Anabaena Cylindrica using Fluoresceinlabeled Lectins. Archives of Microbiology, Volume 201, pp. 17-25

Paddock, M.B., Fernández-Bayo, J.D., VanderGheynst, J.S., 2020. The Effect of the Microalgaebacteria Microbiome on Wastewater Treatment and Biomass Production. Applied Microbiology and Biotechnology, Volume 104(2), pp. 893-905

Patel, V.K., Sundaram, S., Patel, A.K., Kalra, A., 2018. Characterization of Seven Species of Cyanobacteria for High-Quality Biomass Production. Biological Science, Volume 43, pp. 109-121

Pavithra, C.S., Devi, S.S., Suneetha, W.J., Rani, C.V.D., 2017. Nutritional Properties of Papaya Peel. The Pharma Innovation Journal, Volume 6(7), pp. 170-173

Rotem, A., Merchuk, J.C., Arad, S. (Malis)., 1992. Inhibition of the Growth of the Red Microalga Porphyridium Sp. by Limitation of Nutrient Transfer. Journal of Chemical Technology \& Biotechnology, Volume 55(3), pp. 263-267

Rozhan, A.D., 2017. Trends in Production, Trade, and Consumption of Tropical Fruit in Malaysia. FFTC Agricultural Policy Platform. Available Online at https://ap.fftc.org.tw/article/1381

Sarkar, D., Prajapati, S., Poddar, K., Sarkar, A., 2019. Production of Ethanol by Enterobacter Sp. EtK3 During Fruit Waste Biotransformation. International Biodeterioration and Biodegradation, Volume 145, https://doi.org/10.1016/j.ibiod.2019.104795

Septembre-Malaterre, A., Stanislas, G., Douraguia, E., Gonthier, M.P., 2016. Evaluation of Nutritional and Antioxidant Properties of the Tropical Fruits Banana, Litchi, Mango, Papaya, Passion Fruit and Pineapple Cultivated in Réunion French Island. Food Chemistry, Volume 212, pp. 225-233

Singh, R., Parihar, P., Singh, M., Bajguz, A., Kumar, J., Singh, S., Singh, V.P., Prasad, S.M., 2017. Uncovering Potential Applications of Cyanobacteria and Algal Metabolites in Biology, Agriculture and Medicine: Current Status and Future Prospects. Frontiers in Microbiology, Volume 8, pp. 1-37

Sukenik, A., Rücker, J., Maldener, I., 2019. Dormant Cells (Akinetes) of Filamentous Cyanobacteria Demonstrate a Great Variability in Morphology, Physiology, and Ecological Function. Cyanobacteria: From Basic Science to Applications. In: A.K. Misha, D.N. Tiwari, A.N. Rai (ed.), Academic Press, London, pp. 65-77

Souza, R.A.T., Fonseca, T.R.B., Kirsch, L.S., Silva, L.S.C., Alecrim, M.M., Cruz Filho, R.F., Teixeira, M.F.S., 2016. Nutritional Composition of Bioproducts Generated from Semisolid Fermentation of Pineapple Peel by Edible Mushrooms. African Journal of Biotechnology, Volume 15(12), pp. 451-457

Roha, A.M.S, Zainal, S., Noriham, A., Nadzirah, K., 2013. Determination of Sugar Content in Pineapple Waste Variety N36. International Food Research Journal, Volume 20(4), pp. 1941-1943

Sloth, J.K., Jensen, H.C., Pleissner, D., Eriksen, N.T., 2017. Growth and Phycocyanin Synthesis in the Heterotrophic Microalga Galdieria Sulphuraria on Substrates Made of Food Waste from Restaurants and Bakeries. Bioresource Technology, Volume 238, pp. 296305

Stebegg, R., Wurzinger, B., Mikulic, M., Schmetterer, G., 2012. Chemoheterotrophic Growth of the Cyanobacterium Anabaena Sp. Strain PCC 7120 Dependent on a Functional Cytochrome c Oxidase. Journal of Bacteriology, Volume 194(17), pp. 4601-4607

Tonini, D., Albizzati, P.F., Astrup, T.F., 2018. Environmental Impacts of Food Waste: Learnings and Challenges from a Case Study on UK. Waste Management, Volume 76, pp. 744-766 
Vargas, S.V., Santos, P.V., Zaiat, M., Calijuri, M.C., 2018. Optimization of Biomass and Hydrogen Production by Anabaena Sp. (UTEX 1448) in Nitrogen-deprived Cultures. Biomass and Bioenergy, Volume 111, pp. 70-76

Wan, N., DeLorenzo, D.M., He, L., You, L., Immethun, C.M., Wang, G., Baidoo, E.E.K., Hollinshead, W., Keasling, J.D., Moon, T.S., Tang, Y.J., 2017. Cyanobacterial Carbon Metabolism: Fluxome Plasticity and Oxygen Dependence. Biotechnology and Bioengineering, Volume 114(7), pp. 1593-1602 